\title{
Demography, Social and Cultural Characteristics of the Gujjars and Bakarwals, A Case Study of Jammu and Kashmir
}

\author{
Dr.Mohd. Tufail \\ Post DoctoralFellow, Centre for the Study of Regional Development,School of Social Sciences, Jawaharlal \\ Nehru University, New Delhi.
}

\begin{abstract}
Gujjars and Bakarwals is the third largest community in the state of Jammu and Kashmir. They constitute 8.1 percent of the total population in the state according to the census of India, 2001. Gujjars and Bakarwals population is highest in the Jammu region followed by the Valley of Kashmir. It is believed that Gujjars migrated to Jammu and Kashmir from Gujarat (via Rajasthan) and the Hazara district of North Western Frontier Province.Most probably in the 5th and 6th century A.D. at the occurrence of some serious droughts they moved out of Gujarat and crossing Rajasthan and Punjab entered the green pastures of the Siwaliks and the Himalayas. Transhumance practice is the biggest impediment for those who want to ensure formal education for their children. Frequent seasonal migration is one of the biggest hurdles in the education of Gujjar and Bakarwal community.

Due to climatic conditions, which vary from place to place in Jammu and Kashmir, Gujjars and Bakarwals have adjusted themselves to different patterns of life and adjustment. No doubt, Gujjar and Bakarwal in Jammu and Kashmir have taken to the Islamic faith and according to their dress, way of life, marriage and kinship, all are different as compared to their counterparts settled in other parts of the state. Their Gojri language is almost linked with the Rajasthani language and dialect. The Gujjars and Bakarwals settled in the Jammu and Kashmir possess tall personality with the Jewish features. Their dress is conventionally which is more nearer to the Pushto peoples of Pakistan. Gujjar and Bakarwal community have their own cultural and linguistic identity.
\end{abstract}

Keywords: Gujjars and Bakarwals, Demography, Culture, Literacy

\section{Introduction}

It is believed that Gujjars migrated to Jammu and Kashmir from Gujarat (via Rajasthan) and the Hazara district of North Western Frontier Province.Most probably in the 5th and 6th century A.D. at the occurrence of some serious droughts they moved out of Gujarat and crossing Rajasthan and Punjab entered the green pastures of the Siwaliks and the Himalayas. The diffusion and spread of Gujjars in the State of Jammu and Kashmir are not known with certainty. When the Gujjars of Jammu and Kashmir are asked about their place of origin, they simply say that their forefathers had migrated from Gujarat and Rajputana (Rajasthan). The arrival of Gujjars in Jammu and Kashmir is attributed to the outbreak of devastating droughts and famines in Rajasthan, Gujarat and Kathiawad. There are archaeological evidences to prove that there was a spell of dryness in the 6th and 7th centuries in Rajasthan and Gujarat which led to the outmigration of these people, who along with their cattle entered the pastures of the Siwaliks and the Sub-Himalayas. The 'Gujri' language is now recognised to be a form of Rajasthani language, which supports the hypothesis that Gujjars have out migrated from Rajputana (Rajasthan).

In Jammu and Kashmir Gujjar and Bakarwalhave no authentic historical record of their migration. It is difficult to ascertain with exactness the essential features of their migration to the hills of Jammu and Kashmir. The assumption is that the main reasons of their migration were persistent drought, insufficient grazing facilities in their original lands, increase in their population, political or religious persecution in the plains of Punjab by invaders from the west. To quote R.P. Khatana, "they entered by one route or another to seek refuge, in these hills. At times of invasions and persecutions, the flow of refugees from the Punjab plains into the Kashmir hills increased.

\section{Distribution of the Gujjar-Bakarwal Population}

Gujjars and Bakarwals is the third largest community in the state of Jammu and Kashmir. They constitute 8.1 percent of the total population in the state according to the census of India, 2001. Gujjars and Bakarwals population is highest in the Jammu region followed by the Valley of Kashmir. The districts which are highly concentrated by the Gujjars and Bakarwals are Poonch, Rajouri, Anantnag, Udhampur, Kupwara and Srinagar. Kupwara district has 3 percent of the Bakarwals population followed by the Rajouri district having 2.72 percent of the Bakarwals population according to the census of India, 2001. While Udhampur has 1.31 
percent of the Bakarwals population. If we have a look at the Gujjars population, the highly concentrated districts as far the Gujjars population is concerned are Poonch with 39.34 and Rajouri 30.31 percent population. Udhmapur 11.16 percent and Anantnag have 7.14 percentGujjar population. In Rajouri and Poonch they are highly concentrated because these districts have more pasture lands which favours for their livestock for grazing purposes.

In Jammu region they are more in number than the valley of Kashmir because Jammu region is mostly a mountainous area with many pasture lands on the Siwaliks and its PirPanjal ranges which attracts the Gujjars and Bakarwals to settle here. While the district Leh and Kargil has the lowest Gujjar and Bakarwal population.

Distribution of the Gujjar-Bakarwal Population in Jammu \& Kashmir,2001

\begin{tabular}{|c|c|c|c|c|c|}
\hline Districts & Total Pop. & Bakarwals & Gujjars & Gujjars\&Bakarwals & Others \\
\hline Baramulla & 1169780 & 0.3 & 4.4 & 4.7 & 95.3 \\
\hline Srinagar & 1202447 & 0.25 & 3.2 & 3.4 & 96.6 \\
\hline Pulwama & 652607 & 0.08 & 3.13 & 3.19 & 96.9 \\
\hline Anantnag & 1172434 & 1.26 & 7.14 & 8.3 & 91.7 \\
\hline Leh & 117232 & 0.02 & 0.014 & 0.015 & 99.9 \\
\hline Kargil & 119307 & 0.6 & 0.18 & 0.78 & 99.9 \\
\hline Rajouri & 483284 & 2.72 & 30.31 & 33.19 & 67.9 \\
\hline Jammu & 1588772 & 0.099 & 3.81 & 3.19 & 97.8 \\
\hline Kathua & 550084 & 0.5 & 2.75 & 3.23 & 97.7 \\
\hline Total & 10143700 & 0.59 & 7.52 & 8.1 & 91.9 \\
\hline
\end{tabular}

The total Gujjar and Bakarwal population in Jammu and Kashmir is 8.1 percent. The Gujjar population is 7.5 percent whereas the Bakarwal population comprises 0.59 percent in the state.

\section{Age Composition}

India's long experience with high birth rates and rapid population growth has imposed a substantial burden of youth dependence on the Indian economy. The situation is almost same among the Gujjars and Bakarwals community where half of the population is below 24 years of age. Among the Bakarwals population more than 60 percent of the male population is under 24 years of age, whereas more than 58 percent of the female population is under 24 years of age.

If we have a look at the Gujjars community 60 percent of its male population is under 24 years of age and more than 58 percent of the female population in this age group as it is shown in the (table 2.2). Below 10 percent of the Gujjar and Bakarwal population is above 50 years age group.

If we have a look on the age composition ,according to the Census of India, 2001, in the children's age group of 0-5Bakarwalshave 14.4percent of its population in proportion to its total population, Gujjars has a 13.8 percent population of childrenwhereas among the general population it is too low i.e. 12.3percent in comparison to the Gujjars and Bakarwals in proportion to its total population. In the adolescent age group Gujjars and Bakarwals have more population as compared to the general population. Here we can say that fertility rate is more among the Gujjars and Bakarwals in comparison to General population. In the elderly age groups Gujjars and Bakarwals have a better position in comparison to the General population. Number of Elderly population is surviving in the tribal than the general population in proportion to its total population.

The age distribution of Gujjars and Bakarwals is typical of a population that has recently experienced a fertility decline. The age-sex pyramid also indicates higher old age mortality and lower life expectancy. More than 50 percent of the population of Gujjars and Bakarwals is below 19 years of age. Among the general population 48 percent of the population is below 19 years of the age. 6.7 percent of its population is above 60 years of age whereas among the Gujjars 7.6 percent and 6.9 percent among Bakarwals are above 60 years of age

Broad base population pyramid for Gujjars and Bakarwals reflects a 'Young' 50 percent or more of the population being under 19 years. 


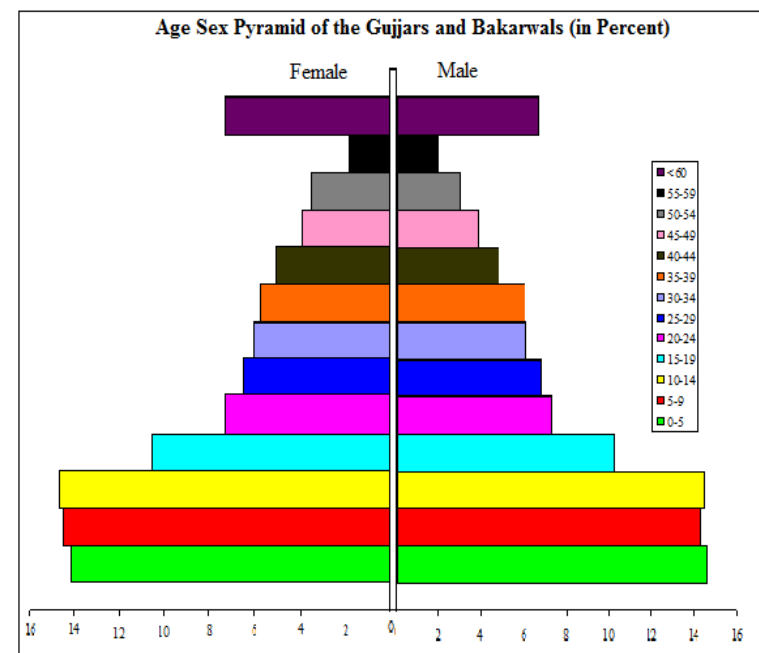

Source: Field Work, (2001)

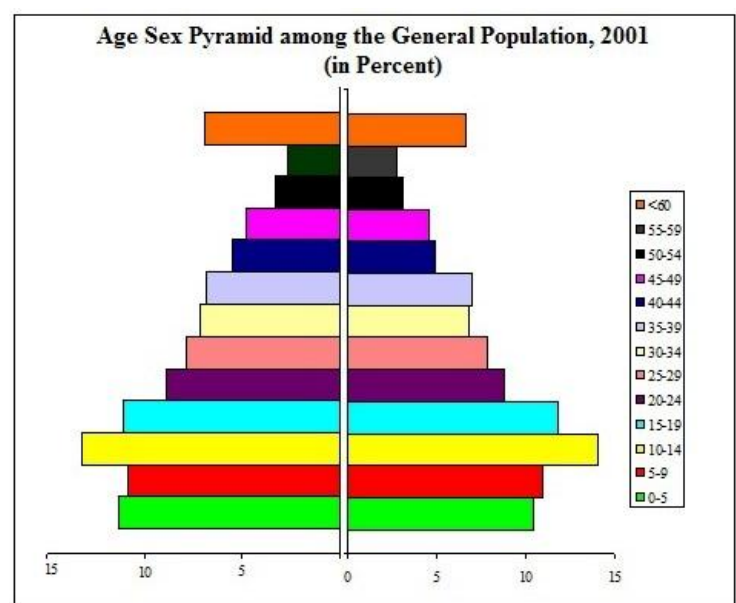

Source: Census of India, 2001

Distribution of Gujjars\&Bakarwals by Age and Sex (in Percent)

\begin{tabular}{|c|c|c|c|c|}
\hline $\begin{array}{c}\text { Age Group } \\
\text { (in years) }\end{array}$ & Male & Female & Total & Sex Ratio \\
\hline Below 5 & 12.3 & 11.9 & 12.1 & 819.0 \\
\hline $6-10$ & 14.2 & 13.6 & 13.9 & 806.6 \\
\hline $10-14$ & 12.3 & 12.3 & 12.3 & 843.6 \\
\hline $15-19$ & 10.5 & 10.5 & 11.7 & 844.4 \\
\hline $20-24$ & 11.8 & 11.5 & 10.3 & 921.8 \\
\hline $25-29$ & 9.9 & 10.7 & 9.6 & 865.9 \\
\hline $30-34$ & 9.5 & 9.8 & 5.5 & 791.7 \\
\hline $35-39$ & 5.6 & 5.3 & 5.1 & 951.2 \\
\hline $40-44$ & 4.8 & 5.4 & 3.8 & 846.2 \\
\hline $45-49$ & 3.8 & 3.8 & 3.6 & 836.1 \\
\hline $50-54$ & 3.6 & 3.5 & 1.3 & 863.6 \\
\hline $55-59$ & 1.3 & 1.3 & 0.2 & 666.7 \\
\hline $60-64$ & 0.2 & 0.1 & 0.2 & 1000.0 \\
\hline 65 above & 0.2 & 0.2 & 100.0 & 843.4 \\
\hline Total & 100.0 & & & \\
\hline Source: Field Work, $(2011)$ & & & & \\
\hline
\end{tabular}

\section{Sex Composition}

The sex composition of the population of a particular place is expressed in terms number of females per thousand males. Biological, economic, social and religious aspects of an area influence sex ratio. Economic 
factors are most important among these particularly in the hilly areas which have recently been opened up. The unfavorable sex ratio is considered to be an important indicator of the inequality between males and females in a society.

As we have a look on the sex ratio of Jammu \& Kashmir, which was once hailed by the United Nations Children's Fund (UNICEF) in its 1994-96 study as a place where no female foeticide took place, has suddenly become adverse to the fairer sex. According to the Census of India, 2001, Jammu and Kashmir has shockingly 891 females as compared to the 1000 males, in comparison to the national sex ratio of 933 . This declining trend of the sex ratio is a dangerous drift for the humanity.

Like many other districts of India, the sex ratio has been unfavorable in the Jammu and Kashmir where females are less in number than the males.

\begin{tabular}{|c|c|c|c|}
\hline \multicolumn{4}{|c|}{$\begin{array}{c}\text { District Wise Sex Ratio among the Gujjars\&Bakarwals and } \\
\text { General Population in Jammu \& Kashmir }\end{array}$} \\
\hline Districts & Bakarwals & Gujjars & General Pop. \\
\hline Kupwara & 982.0 & 925.4 & 905.6 \\
\hline Baramulla & 802.6 & 905.1 & 902.7 \\
\hline Srinagar & 807.9 & 929.5 & 851.4 \\
\hline Badgam & 584.9 & 974.5 & 930.1 \\
\hline Pulwama & 883.2 & 906.6 & 944.9 \\
\hline Anantnag & 854.6 & 891.3 & 922.2 \\
\hline Leh & 0.0 & 0.0 & 823.0 \\
\hline Kargil & 910.5 & 744.2 & 836.8 \\
\hline Doda & 866.7 & 889.9 & 903.4 \\
\hline Udhampur & 872.9 & 889.0 & 860.2 \\
\hline Poonch & 943.2 & 931.4 & 918.6 \\
\hline Rajouri & 898.8 & 894.2 & 878.0 \\
\hline Jammu & 834.7 & 912.7 & 868.5 \\
\hline Kathua & 848.3 & 919.8 & 900.8 \\
\hline Total & 867.9 & 908.0 & 891.0 \\
\hline sus c & & & \\
\hline
\end{tabular}

The sex ratio among the Gujjars and Bakarwals is highly imbalanced. In the above table it has been seen that sex ratio among the Gujjars and Bakarwals is too low. The sex ratio among Gujjars is 908, comparatively better than the general population sex ratio of 891.If we have a look at the district wise sex ratio among the three communities of population in Jammu and Kashmir. Gujjars have a better sex ratio than the Bakarwals and General Population. Bakarwals have a very low sex ratio in all the districts of Jammu and Kashmir which shows that there could be many reasons behind the less number of its females it could be higher maternal mortality rate, negligence of the females etc among them.

Marital Status: A look at the marital status of females in Gujjars and Bakarwals suggests that among the Illiterates average marriage age is too low in comparison to the educated population. The average age of marriage for the illiterate population is 17.1 in comparison to the 19.2 of the educated population. Further sedentary population has 18.4 average marriage age in comparison to 17.3 of transhumantpopulations. In the males sedentary population has 21.7 and transhumant has 20.5 average marriage ages.

It is quite clear that sedentary population is more educated and subsequently they prefer to marry in latter ages in comparison to the transhumant population. Overall, Gujjars and Bakarwals women marry at younger ages than Gujjars and Bakarwals men, which is a common practice among the Indian tribes.

\begin{tabular}{|l|c|c|}
\hline \multicolumn{2}{|c|}{ Age at Marriage of Different Classes among the Sample households } \\
of theGujjars and Bakarwals
\end{tabular}




\section{Rural and Urban Composition}

Majority of the Gujjars and Bakarwals population is rural in character; almost all of the Bakarwal population (98.7 percent) in Jammu and Kashmir is rural. Only 0.85 percent population is urban in character among the Gujjars and 0.03 percent among Bakarwals. Whereas 26.8 percent of the Population is Urban among the General population. Transhumance occupation does not favour urban areas, rural areas and pastures are the necessity of the transhumant population to graze their animals.

In all the districts, urban population of the Gujjars and Bakarwals is too low in comparison to the General Population; no district has above one percent urban population of the Bakarwals.

Distribution of the Urban Population of Gujjar-Bakarwals and Others

\begin{tabular}{|c|c|c|c|c|c|}
\hline Districts & Total Urban Pop. & Bakarwals & Gujjars & Gujjars\&Bakarwals & Others \\
\hline Kupwara & 25495 & 0.11 & 1.8 & 1.9 & 6.0 \\
\hline Baramulla & 196322 & 0.04 & 0.2 & 0.2 & 7.8 \\
\hline Srinagar & 946166 & 0.009 & 0.05 & 0.05 & 37.6 \\
\hline Badgam & 70588 & 0 & 0.4 & 0.4 & 2.8 \\
\hline Pulwama & 68507 & 0 & 0.5 & 0.5 & 2.7 \\
\hline Anantnag & 168363 & 0 & 0.15 & 0.15 & 6.7 \\
\hline Leh & 28639 & 0 & 0 & 0 & 1.1 \\
\hline Kargil & 10657 & 0 & 0 & 0 & 0.4 \\
\hline Doda & 47695 & 0.35 & 0.42 & 0.7 & 1.9 \\
\hline Udhampur & 116627 & 0.13 & 1.2 & 1.3 & 4.6 \\
\hline Poonch & 23978 & 0.4 & 5.5 & 5.9 & 1.0 \\
\hline Rajouri & 33655 & 0.2 & 5.4 & 5.6 & 1.3 \\
\hline Jammu & 701218 & 0.03 & 1.96 & 1.99 & 27.9 \\
\hline Kathua & 78728 & 0.01 & 1 & 1.01 & 3.2 \\
\hline Total & 2516638 & 0.03 & 0.85 & 0.88 & 26.8 \\
\hline
\end{tabular}

\section{Social Characteristics}

Education Level

Transhumance practice is the biggest impediment for those who want to ensure formal education for their children. Frequent seasonal migration is one of the biggest hurdles in the education of Gujjar and Bakarwal community.

According to the JavedRahi about five lakh nomadic Gujjars and Bakarwals mostly remain illiterate due to lack of education facilities in the higher reaches of the state. Though desirous of having formal education, these nomads are not in a position to relinquish their lifestyle.

It is quite clear from the below tables and figures that educational level among the Gujjars and Bakarwals is not impressive. The analysis shows that the majority of the population is illiterate, in the total 31.65 percent of the population is literate in the Gujjars community,22.51percentis literate among the Bakarwals. If we compare it to the General population, the general population has 71.23percent of the literacy rate. In all the districts General population hasthe highest literacy rate in comparison to the Gujjars and Bakarwals, because Gujjars and Bakarwals do not have a fixed place and they keep moving all around the year so they get less opportunity of educating their children as compare to the settled general population.

\section{District wise literacy Rate}

After having a closer look at the district wise distribution of literacy among Gujjar and Bakarwals in the below table, the high literacy is found among the Bakarwals population in the districts of Poonch, Rajouri and Jammu which has 30.8, 20.5 and 23.5 percent educated population of them respectively. Whereas among the Gujjars Jammu has 39.00, Poonch34.60 andRajouri 32.94 percentliterate population (table 2.8). These aremost literate districts as far as the literacy among the Gujjars is concerned. Among the general population all the districts have more number of educated peoples than the Gujjars and Bakarwals.

Gujjar and Bakarwals are highly marginalized and illiterate in comparison to GeneralPopulation of the state. Gujjars and Bakarwalsare a tribe which hasthe lowest enrollment in school education in Jammu and Kashmir. In many Gujjar and Bakarwal areas, there is no school available at all, and in other areas, enrollment is only 20 to 30 percent. Education is the myth to sedentarisation or the permanent settlement of the nomads, their education problem is due to the transhumance practice and these problems will disappear in the near future when they will be settled permanently. 
Literacy Rate among the Gujjar-Bakarwals and General Population in

Jammu and Kashmir (in Percent)

\begin{tabular}{|c|c|c|c|c|}
\hline Districts & Total Lit. Pop. & Bakarwals & Gujjars & General Pop. \\
\hline Kupwara & 232,557 & 20.4 & 16.9 & 65.32 \\
\hline Baramulla & 447,075 & 19.3 & 19.7 & 62.48 \\
\hline Srinagar & 641,267 & 15.6 & 16.3 & 78.83 \\
\hline Badgam & 226,167 & 18.3 & 21.7 & 74.23 \\
\hline Pulwama & 281,518 & 20.1 & 17.4 & 66.21 \\
\hline Anantnag & 463,197 & 14.6 & 15.5 & 73.01 \\
\hline Leh & 68,278 & 100.0 & 88.2 & 68.21 \\
\hline Kargil & 60,803 & 17.4 & 50.7 & 63.98 \\
\hline Doda & 274,425 & 15.6 & 16.8 & 54.82 \\
\hline Udhampur & 343,429 & 19.3 & 21.3 & 61.21 \\
\hline Poonch & 156,398 & 30.8 & 34.6 & 69.08 \\
\hline Rajouri & 234,228 & 20.5 & 32.9 & 72.45 \\
\hline Jammu & $1,070,574$ & 23.5 & 39.0 & 79.07 \\
\hline Kathua & 307,370 & 18.8 & 19.3 & 74.11 \\
\hline Total & $48,07,286$ & 22.51 & 31.65 & 71.23 \\
\hline
\end{tabular}

From the below tables 2.9, 2.10 and 2.11 it is quite clear that less number of people are educated in the higher education.Most of the Gujjars and Bakarwals are educated up to primary or middle level. During the migratory life most of them left their education at primary level. Since they have mobile schools and they are up to $5^{\text {th }}$ standard only, which keep moving with community members during theirtranshumance practice. So, after $5^{\text {th }}$ class there is no education facility which force the community members to dropout from the education. In the general population (table 2.11), there isa more educated population in higher education than the Gujjars and Bakarwals because they are sedentary and get more opportunity to educate their children.

If we have a close look at the level of education in the different age groups of the sample households, 46.7 percent are below primary, 27.5 percent are up to middle, 14.9 percent up to high, 7 percent up to higher secondary and 3.9 percent are graduates. Huge chunks of Gujjars and Bakarwals are below middle. As far as the male and female population is concerned, 29.1 percent males are below primary in comparison to 17.6 percent of the females. 18.1 percent males are educated up to middle in comparison to 9.4 females. Males have a larger share in higher educationin comparison to the females.

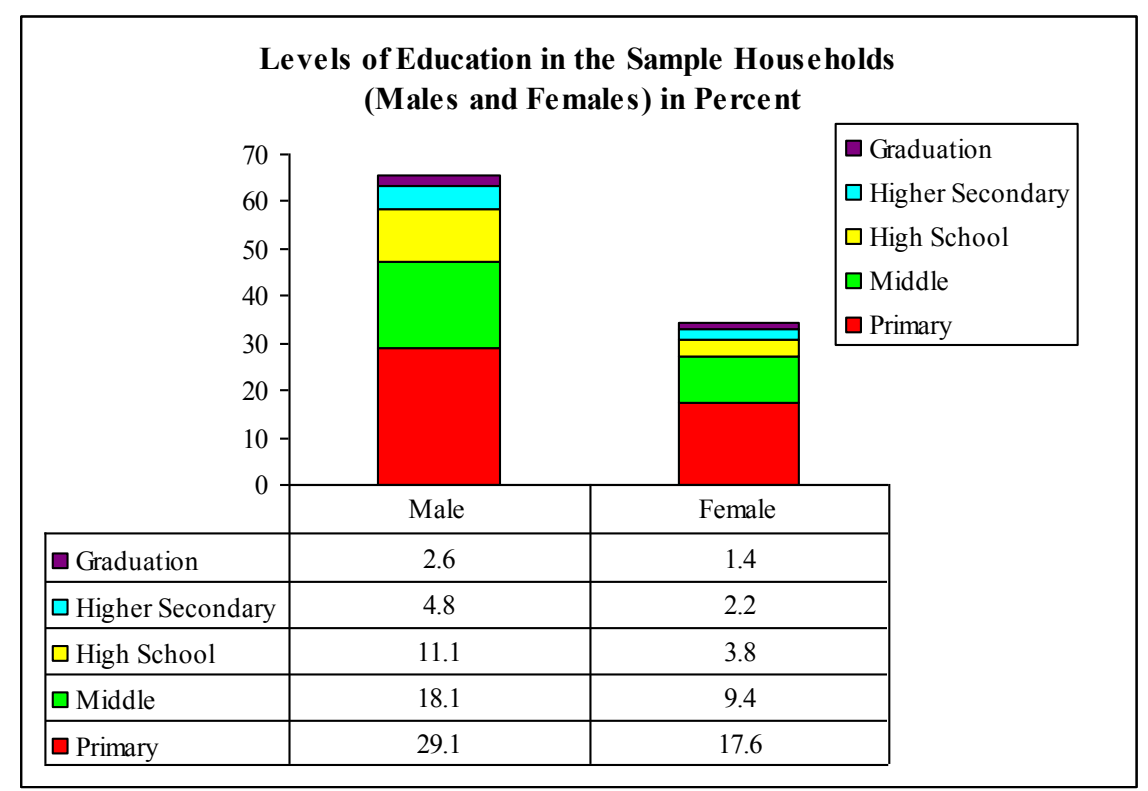

Source: Field Work (2011), Note: Sample Size: 210 


\section{Challenges of Educational Services in the Gujjar and Bakarwal Areas}

The literacy rate among the Gujjar and Bakarwals is too low as compare to other inhabitants of the state. In the hard and harsh climate for the teaching in the schools resulting in teacher shortages and poorly motivated teachers in schools leads to the poor education. A visit to some schools during the field work found as 50 students per teacher. In some cases teachers do not attend schools due to poor monitoring mechanism in such schools. Lowe income of the parents which makes difficult for them to pay tuition fee, uniform and other contributions to schools.Parents tends to use their children for their domestic as well as rearing livestock activities because of which poor attendance of students was noticed in schools. One of the serious issue of the transhumance mobility of the Gujjars and Bakarwals as they take more along with their families including children which lasts 3-4 months in a year, during this time childrens remain absent from the schools. Due to terrorist activities mobile schools were seriously affected and many of them being shut down. This has seriously effected the schools education and hence there are a huge illiterates or lower level of education among the Gujjars and Bakarwals.

\section{CulturalCharacteristics of the Gujjars and Bakarwals Introduction}

Due to climatic conditions, which vary from place to place in Jammu and Kashmir, Gujjars and Bakarwals have adjusted themselves to different patterns of life and adjustment. No doubt, Gujjar and Bakarwal in Jammu and Kashmir have taken to the Islamic faith and according to their dress, way of life, marriage and kinship, all are different as compared to their counterparts settled in other parts of the state. Their Gojri language is almost linked with the Rajasthani language and dialect. The Gujjars and Bakarwals settled in the Jammu and Kashmir possess tall personality with the Jewish features. Their dress is conventionally which is more nearer to the Pushto peoples of Pakistan. Gujjar and Bakarwal community have their own cultural and linguistic identity. This section deals with the Society and culture of Gujjars and Bakarwals and the varied geographical settings in which the tribes live. Naturally the different aspects of their culture have to be explained in terms of their geographical settings. Since the Gujjar and Bakarwals live in the isolation for centuries. They have developed a culture of their own adjusting with their local environment. But from the past few years the tribal indigenous culture has been changed with the introduction of Industrialisation, urbanization and several other factors like disturbed condition in the state during the last twenty years. The cultural characteristics of the Gujjars and Bakarwals are given under the following headings.

\section{Family Structure and Marriage practices}

From the below figures, it is quite clear that still 78 percent of the Gujjars and Bakarwals population is living in the joint families and 22 percent are living in the single families. If we have a close look on the family size, 12 percent of the families having more than 10 family members, 23.5 percenthas 8 to 10 family members, 35 percent has 6-8 family members where as 19.5 percent families have $4-6$ family members per family. Generally the community has larger family system because in the transhumant society larger family is the necessity for keeping livestock.

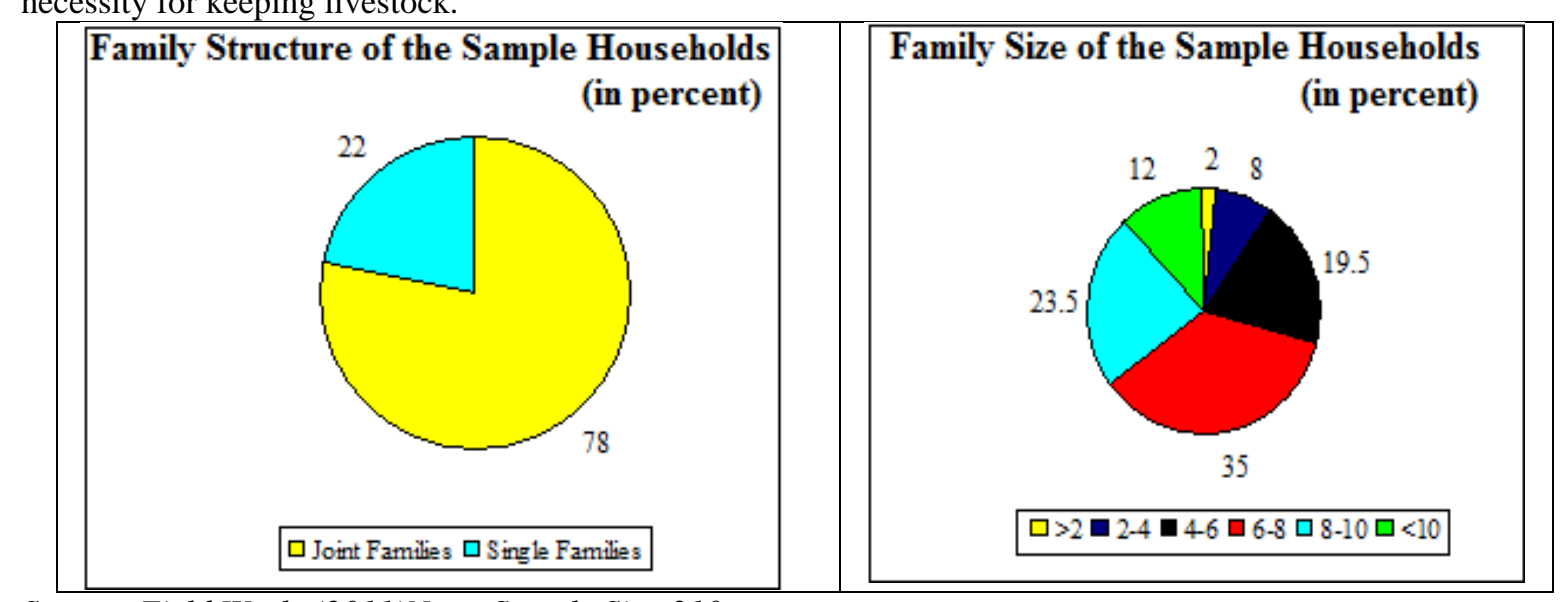

Source: Field Work, (2011)Note: Sample Size-210

The study indicates that majority of the respondents 72 percent prefer early marriage of their sons and daughters due to mass illiteracy, orthodoxy, outcaste threat and prevailing insecurity caused by militancy and allied factors, Majority of the respondents 97 percent observe marriage within the caste, less than 3 percent marriages are performed by love. In the past polygamous pattern was also performed but major change has taken place in this custom now. It was a common practice few years back when the Gujjar and Bakarwalhave a big number of 
herds and are rich at that time but now most of them left with the occupation and prefer to marry once a time in the life. They generally wear silver ornaments like Jumka, Kangan, Sierie(necklace), long, Challa, Payal, but among some people the gold jewellery is considered as the status symbol. They wear salwarkameez.

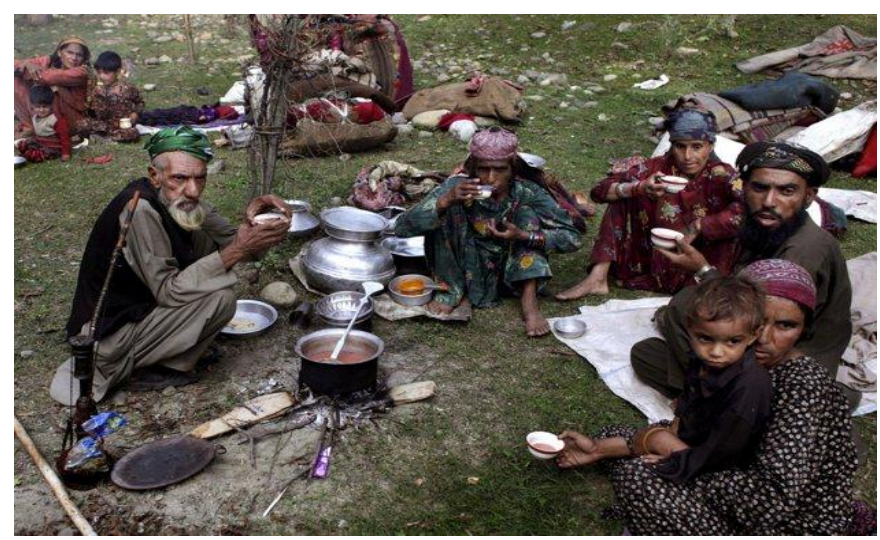

Haltof Gujjar and Bakarwal Joint Kunba (family) during the Seasonal Migration

If we look at the marriage age in different age groups among the male and females in the community, it is clear that male prefer to marry in the age group of 20-25 while the majority of the females are being married in the 15-20 years of age. While only 13 males are married after crossing the age of 30 while 2 females are married after crossing this age.

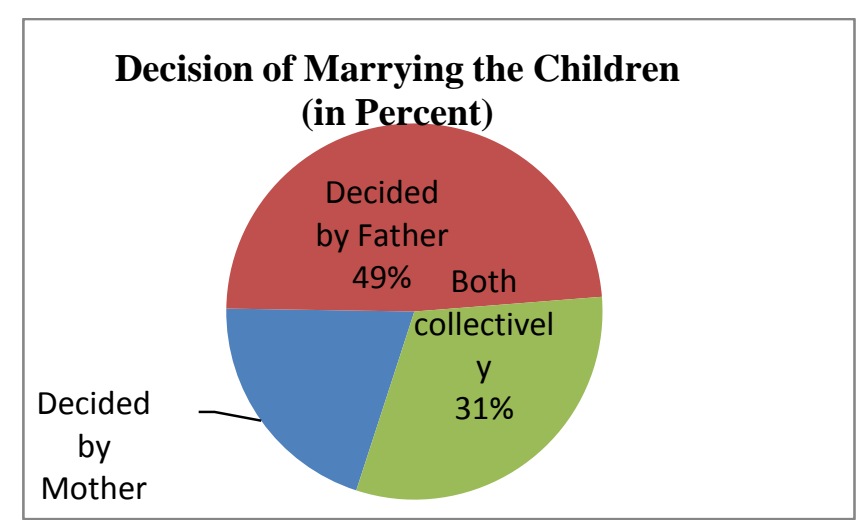

Source: Field Work (2011), Note: Sample Size-210

If we have a look at the role of father and mother in deciding the marriage of their children. From the above diagram 2.8 it is clear that 49 percent of the fathers have an exclusive say in deciding the marriage partners of their children. While 20 percent of the mothers decide the marriages of their children and 31 percent collectively. From the figures it is clear that males have a larger role in the community.

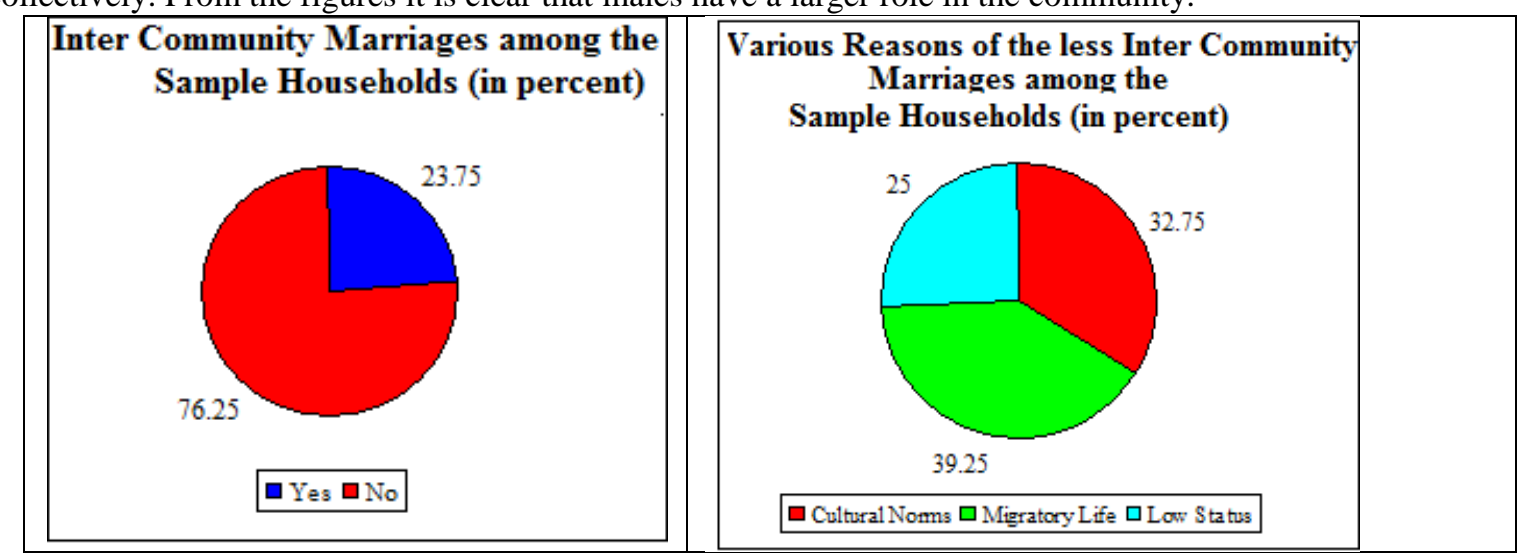

Source: Field Work, (2011), Note: Sample Size-210

From the above figure, it has been seen Inter-community marriages among the community members rarely exist, 23.25 percent of the families think that inter-community marriages exist. While a larger chunk 76.75 percent do not allows for the inter-community marriages. The reason behind the non-existence of inter-community marriages are low status, migratory life, cultural norms etc. 39.25 percent of the families have the views that due 
to migratory life of the community inter community marriages does not exist among the transhumant and sedentary groups of tribal. 32.75 percent thinks that cultural norms are responsible for the non-existence of inter-community marriages and 28 percent families hold low status as a reason responsible for the non-existence of inter-community marriages.

\section{Food Habits}

Since the Gujjar and Bakarwals live in the secluded conditions, their livelihood pattern, food and dietary practices and their attitude to various aspects of life, may often differ from those of the non-tribal population. This is reflected in their dietary habits (Sharma, Anita, 2009). Due to changing agricultural system in the cropping pattern food habits for many of the communities undergone some changes and it was noticed in the Gujjar and Bakarwal community too.

Maize is the staple food of the mountainous peoples particularly Gujjar and Bakarwal as it gives the warmth and strength which the body is needed especially in winter. Maize is grown in the hilly and mountainous areas and it is a tropical crop in this region. The cultivation of the maize is done by the Gujjar and Bakarwal community as it is grown in mountainous areas and majority of the nomads are settled in these areas. Other crops like rice, wheat etc need irrigation which is not so much developed in the tribal areas of Jammu and Kashmir. So they left the only option to cultivate the maize. Mostly they depend on milk products as their staple food besides cereals, wheat and maize. They may be vegetarians and non-vegetarians as well. The favourite dishes of Gujjar and Bakarwal are "Maki ki Roti" Ganhar / Sarssoonko Sag, Lassi, Kalari, Karan, etc. It is surprising that Gujjar and Bakarwal are mostly vegetarians.

From the below table, it is clear that the staple diet of the Bakarwals is maize roti, noon cha and goat milk. 91 percent of the households take maize roti, 100 percent of them are addicted of noon cha, an interested thing about them only 13.5 percent of them take lipton tea. The Bakarwal to eat bread cooked from both maize and wheat flour. Some of them take rice too.

They simply cannot do any work without daily doses of Noon Cha or the salt tea. The shopkeepers in the Heerpura of Pulwama district told that about a decade ago the Gujjar and Bakarwal drunk only Noon Cha and not tea with the sugar (called lipton cha by the Gujjar and Bakarwal) but now there is a small but growing demand for the regular tea with sugar. However, while for the majority of the Gujjar and Bakarwal favourite tea as remains noon cha some of them have started to enjoy the occasional pleasure of sweetened tea.

Food items consumed by the Community (in percent)

\begin{tabular}{|c|c|}
\hline Food items & Percent \\
\hline Maize & 91 \\
\hline Wheat & 26 \\
\hline Rice & 93.5 \\
\hline Namkeen cha (Salt tea) & 100 \\
\hline Libton cha (tea) & 13.5 \\
\hline Jawahar & 2 \\
\hline Lassi & 83.5 \\
\hline Milk & 88 \\
\hline Other Milk Products & 66 \\
\hline Cauliflower/cabbage & 22 \\
\hline Kadham (auk) & 16 \\
\hline Onion & 67.5 \\
\hline Patato & 47.5 \\
\hline Other vegetables & 80.5 \\
\hline Maize & 91 \\
\hline Wheat & 26 \\
\hline
\end{tabular}

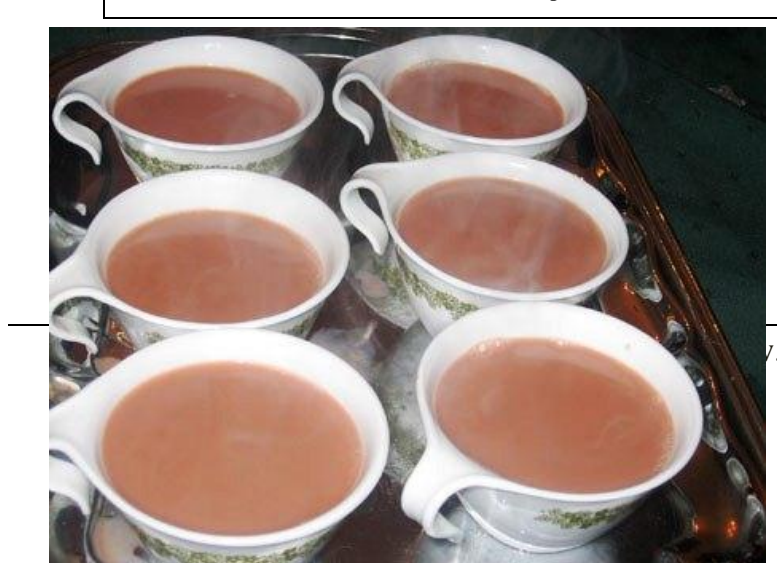

Noon Chayepayalisof the Gujjars and Bakarwals

Besides maize and other milk products Gujjar and Bakarwal also use various plants as food. Gordi is after like plant that is collected from the forests and use to make a simple yet delicious saag or vegetable. 


\section{Festivals}

Many festivals celebrated by the Gujjars and Bakarwals are common among the Muslim brothers from Kashmir but few of them are celebrated by the Gujjars and Bakarwals only like Baiskahi, lighting lamps on the graves and shrines which are very close to the Hindus of north India. Festivals are of part and parcel for Gujjar and BakarwalTribal Community. They celebrate all the festivals of national significance apart from these Gujjar and Bakarwaltoo have incorporated their religious beliefs and customs. These are the important festivals for their society which they celebrate with great festivity and enthusiasm. The main religious activities and festivals observed by the Gujjar and Bakarwal community are five times prayers, fasting in the month of Ramdhan, IdulFitar, Idul-Zaha, Naoroz and Baisakhi. They start their upward journey after the celebration of Baisakhi festival in April. But since most of them left the seasonal migration, so importance of the Baisakhi festival is declined in the community. This Baisakhi festival has a great significance in the Gujjar and Bakarwal life and in particular for the start of seasonal migration in April. During the course of annual migration, they pass from many shrines and graves of the pirs (holy men). If a death occurs during the migration, the dead is buried somewhere somewhere along the route. They heap up stones on the grave and every year as they pass through the route they pay respect to the departed soul and light a lamp on the grave. Most of the Gujjars and Bakarwalshave a joint family system (Sharma, Anita, 2009).

\section{Religious Practices}

Religion underlines the integrity of the family as the foundation of the faith, and recognizes that the key to family integrity is maintaining traditional roles for women. Most native Kashmiris hold the Gujjar and Bakarwalto be strict Muslims of a deeply religious nature. During the field work, I found that a larger number of the Gujjar and Bakarwalgrow their symbolic beard and moustache as compared to other Kashmiris. They seem to be rather proud of these external statements, caressing their beards lovingly or decisively every now and then (Sharma, Anita 2009).

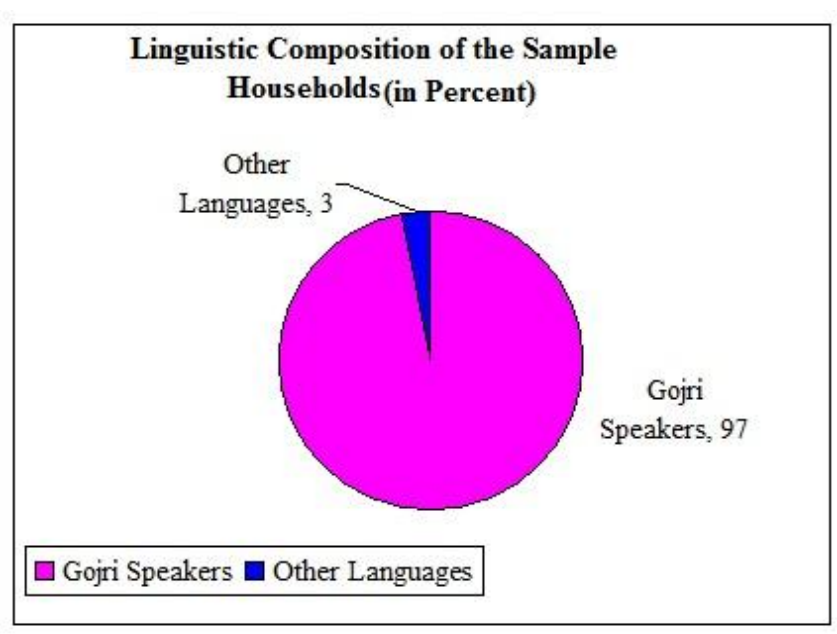

\section{Language}

The Gojri language is the language of all the Gujjar and Bakarwal. The Gujjar and Bakarwalof Jammu and Kashmir have managed to retain their language which continues to be akin to Rajasthani rather than Pahari. Griersonwas of the opinion that the Gojri spoken by the Gujjars of the submontane districts of the Punjab and Kashmir was allied to Rajasthani. Grierson opined, "One of the two things is quite certain. Either Gojri is a form of Rajasthani and conversely, Rajasthani is a form of Gojri and resemblance of Gojri to Mewari is very striking. But still closer is the resemblance of Gojri to Mewari dialect of Rajasthani spoken in Alwar, some distance to the north of Mewar and separated from that state by the territory of Jaipur".Gojri speakers constitute the third largest group in Jammu and Kashmir State after Kashmiri and Dogri speakers being at first and second position respectively.

Gojri one of the oldest and significant languages of the South Asian Sub Continent. According to a current analysis the Gojri language is the first language of 20 million people in South Asia and nearly eight million people in India majority of them in the Jammu and Kashmir State. The Government of the Jammu and Kashmir has already recognised Gojri by including it in the sixth schedule of the constitution. Gojri is one of the ancient languages of India. In well documented pieces of the works the historians have traced the origin and practice of Gojri language since BC era. In the sample population 97 percent are Gojri speakers and 3 percent speaks other languages, as shown in the figure. 


\section{Dress and Ornaments}

BakarwalGujjar mostly wear ShalwarQamiaz, Vaskat, Angoo and Pagheri (Headgear) while their Women folk Wear long Gown called Jubo, Pheerni, Shawl, Cap and Jotti, Jora. Dodhi Gujjar wear "Pagh" Qameiz and Tehmad while their ladies wear Shirt with strips Choridarshalwar and Jotti. The dress of the Gujjars and Bakarwals is quite different from the Kashmiris and Dogras.

Gujjar and Bakarwal men and women wear salwarkameez. The salwar worn by both men and women is known as suthan and the kameez as peherni or kurti. Gujjar and Bakarwalmen also wear a jacket known as basket on the kameez, their turban is known as turban is known as patka or lungi. In the winter men also wear a coat, and shawl known as chadri, to keep warm in the bitter cold. Women wear a chuuni known as chipri with their salwarkameez. A smaller triangular scarf mainly worn by the younger women is kasawa. The embroided cap worn by the Gujjar and Bakarwalwomen is aptly called as lachka (Sharma, Anita 2009).

According to field work many of the community members have left the wearing of traditional dresses. Male clothing usually includes a salwarkameez upto knees (dress), lunge (turban), fortypercent of the male have already left the turban wearing culture. Due to the disturbed conditions and shift towards the sedentarisation it is great threat to the culture of the community. Among the sample population 59 percent still wear turban and 41 percent left the turban wearing culture, as shown in the figure 2.12.

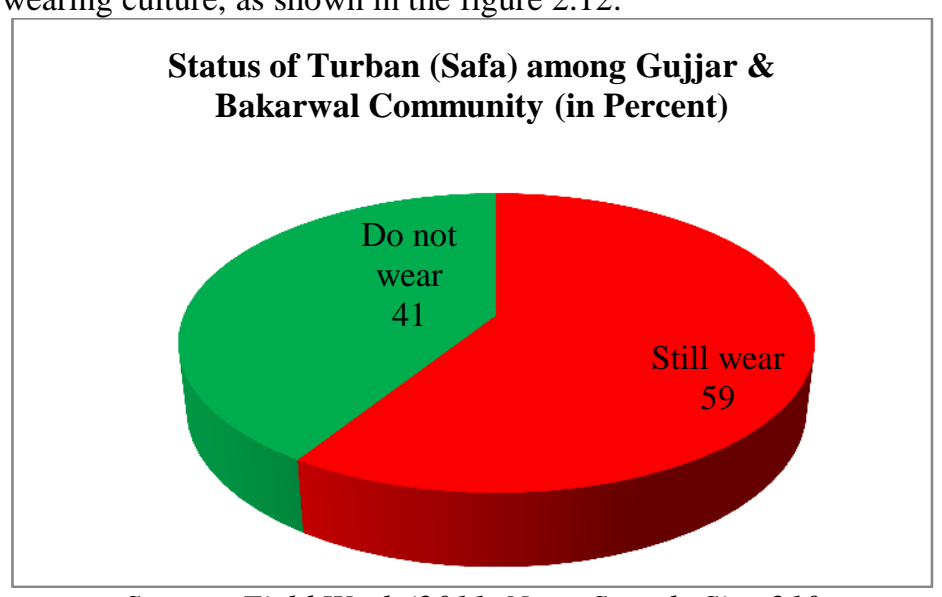

Source: Field Work (2011, Note: Sample Size-210

\section{Jirga councils or Tribal Councils}

Jirga is a Persian word. It means a gathering, a public, a "Panchayat" or a consultation. According to Henry Maine (1946) except custom there is no written law in the world and it is an accepted truth and this truth is either good or bad and the custom is the traditional or indigenous system of the social control. According to figure 2.13, 58 percent of the Gujjars and Bakarwals still practice Jirgas and settle their cases within their community while 42 percent have the views that jirgas do not exist now and they settle their cases with the help of police and modern courts.

Nowadays the institution of the panchayti raj is working in the tribal areas of the Jammu and Kashmir. The panchaytssamitis were introduced in the Jammu and Kashmir. The traditional panchayts had lost its ground in some of the places. Based on this belief, the Gujjar and Bakarwalsystem of law is executed for the benefit and with the consent of the entire community. The administrative system is controlled by the clan chiefs or sardars. The Gujjar and Bakarwalare dispersed over a larger area, so each clan has its own chief. These are prominent men of the clan who are respected by all the clan members. They are chosen on the basis of their stature in the community, sense of the fair play and oratory skills. Sardars are the only recognized administrative heads in the Gujjar and Bakarwalcommunity and even today, they resolve nearly all disputes among their clan members. Each sardar works with a couple of informally appointed salakars or advisors who are consulted, along with other elders and prominent men of the community. The control exercised by the sardar over his clan members is absolute, however clan is wielded in a humane manner and all effort is made to resolve conflicts and end pervading tensions.

In the past, the chosen sardars prevailed over all disputes in their respective bradris. At times, when solution could not be achieved by a sardar, the matter would be taken to another group of the prominent men, who were held in the high esteem. The moulvai or the priest plays a significant role in the execution of the Gujjar and Bakarwallaw. He is often summoned by the saradr to facilitate in the performance of the ritual of oath during prosecution. The centrality of the Quran and the faith vested in the oath should also be mentioned. The Gujjar and Bakarwalbelieve that anyone who commits perjury will be punished visibly within days of committing the sin and narrate the incidents on how perjures have suffered divine intervention. 


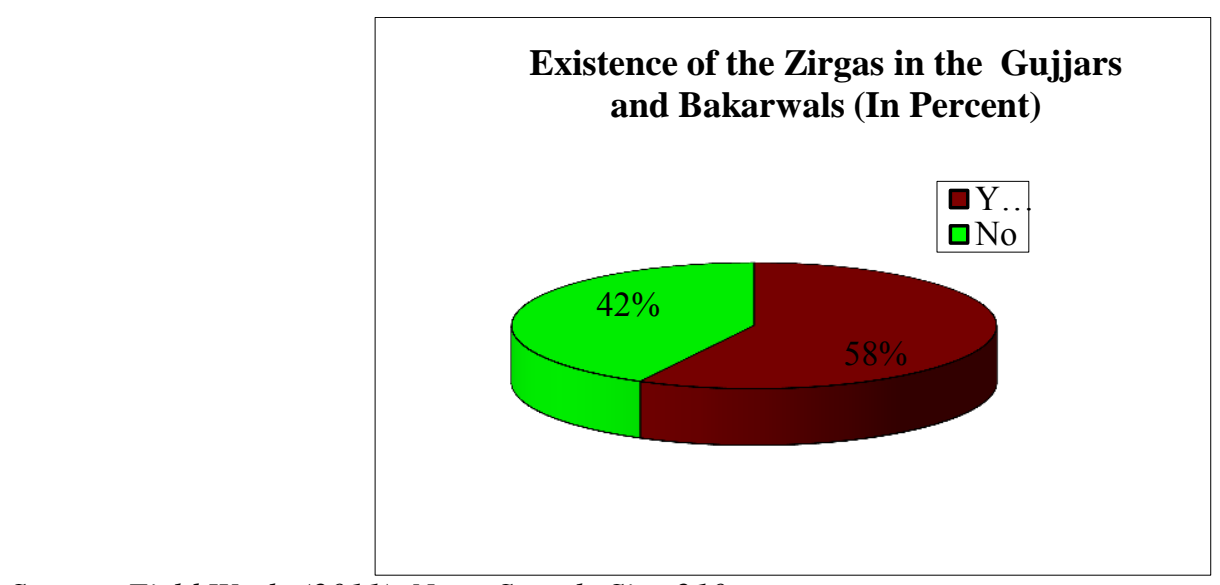

Source: Field Work, (2011), Note: Sample Size-210

The Gujjars and Bakarwalsprefer to keep their disputes out of the courts. Being mostly illiterate, they shy away from paperwork and also seldom trust a system steeped in procedural requirements. Being a nomadic and reserved people, even today they seldom muster the courage to overrule the authority of their sardars to seek justice from the state administration, as breach of the norm may result in adverse social repercussions for the individual and his family. Maintaining the respect due to the sardar is essential even while approaching modern judiciary and administration. However, exceptions exist and are said to be on the rise, with instances of the people overruling the authority of the sardar in order to adopt modern legal procedures becoming more frequent. By way of conclusion it can be said that customary laws regulates social relations among the members of the society. It facilitates the social control in the Biradari of Gujjar and Bakarwals. A breach of the tribal laws forms the subject matter of dispute and may lead to the serious consequences.

\section{Electoral Participation}

Gujjars and Bakarwals are important part of the electoral system looked upon by the political parties. During the present time Gujjar and Bakarwal actively participating in the various levels of elections in Jammu and Kashmir. As their focus towards education is increasing day by day and their interest to participate in the elections is also increasing.

The Gujjar and Bakarwal politics has mainly influenced by Mian Family of WangatKangan, Kashmir. Since 1952, after MianNizam-ud-din (RA) and Mian Bashir Ahmad, MianAltaf Ahmad is representing Gujjar and Bakarwal in the State Legislative Assembly.

From the above table it is seen that Gujjar and Bakarwals actively participate in the elections, 80 percent of the community has the knowledge about elections. 45 percent has the knowledge about the name in voter list, 55 percent do not know about it. 95 percent of them wanted to cast their vote.

Gujjars and Bakarwals Knowledge about the Election Process (in Percent)

\begin{tabular}{|l|c|c|c|}
\hline \multicolumn{1}{|c|}{ Item } & Yes & No & No answer \\
\hline Knowledge of the election data & 80 & 20 & - \\
\hline Knowledge of the name in the voter list & 45 & 55 & - \\
\hline Knowledge of status as voter & 92 & 7 & - \\
\hline Do you prefer to cast your vote & 95 & 5 & - \\
\hline Is it necessary to cast vote for all purposes & 60 & 35 & 5 \\
\hline
\end{tabular}

Historically Gujjar and Bakarwal are affiliated with the National Conference, and they believe that it is the only party which preserves the unity of the state. They hate BJP for its Jammu centric politics which wanted Jammu region as separate state. Most of the Gujjar and Bakarwals are against the trifurcation of the state.

\section{Conclusion}

In this chapter we have seen that Gujjar and Bakarwals are originated from the Central Asian Countries, how they entered India in different periods of the time. In Jammu and Kashmir their migration took place during the drought and famine periods in Rajastahn and Gujrat. In the demography section we have seen that they are in majority in the Jammu Province of the state due to rich resources of pasture lands. The sex ratio among the community is too much low in comparison to the national average. They have distinct culture which differs from other communities in Jammu and Kashmir. Their festivals, marriage practices of them, dress code 
and several other ceremonies performed during the weddings create a distinct image for them in the state. The tribe generally has a joint family pattern which is a necessity for the survival of the livestock occupation but now it is found that due to urbanization, modernization structure of the family is shifted towards the single family. Their dwelling places are known as dera or kacha houses, made up of wooden roof. But some of the families have pacca houses which are being settled in the winter pastures. Their Jirga system from which community members settled their cases will become a history in next few decades, most of the Gujjars and Bakarwals demanded to give it a legal shape so that it should be preserved. Most of the Gujjars and Bakarwals participate in all kinds of elections. Historically they are the vote bank of National Conference. According to them it is the only party which preserves the unity among all the regions of the state.

Due to 20 years of disturbance in the state and shift towards sedentarisation a lot has been changed from their centuries old transhumance and forced shift towards sedentarisation. Changes are found in all aspects of their life. As the country is marching ahead through developmental programmes, Gujjars and Bakarwals are also influenced by it and changes are witnessed in their every walk of life. We can find changes in their social, political, cultural and economic spheres.

\section{References}

[1]. G. A. Grierson, GUJURI(The Language of Gujjars).

[2]. Hussain, Majid, 2006, Geography of Jammu \& Kashmir State, Rajesh Publications, New Delhi.

[3]. Khatana, R.P. (1984) Transhumance Economy of the Gujjars and Bakarwals, Jammu and Kashmir, Ph.D. thesis submitted in the Centre for the Study of Regional Development, School of Social Sciences, Jawaharlal Nehru University, New Delhi.

[4]. Sharma, Anita, (2009), The Bakarwals of Jammu and Kashmir navigating through Nomadism.

[5]. Tufail, Mohd, Declining Sex Ratio in Jammu and Kashmir, Daily Excelsior, http://www.dailyexcelsior.com/web1/12apr02/edit.htm\#5.

[6]. Wazwan is a multi-course meal in Kashmiri cuisine, the preparation of which is considered an art and a point of pride in Kashmiri culture and identity. 